\title{
Aptitude de l'espèce Penicillium caseicolum à la production d'enzymes lipolytiques ${ }^{(1)}$
}

\author{
par \\ G. LAMBERET et J. LENOIR \\ Laboratoire de Recherche de la Chaire de Technologie (I.N.R.A.) \\ Ecole Nationale Supérieure Agronomique de Grignon (78)
}

\section{Sommaire}

L'aptitude de Penicillium caseicolum à la production de lipases a été recherchée sur une collection de près de 100 souches de diverses origines par culture en milieu liquide. L'activité lipasique a été déterminée sur les filtrats de culture par une mesure des variations de $\mathrm{pH}$ d'une émulsion de tributyrine faiblement tamponnée.

Les souches de $P$. caseicolum révèlent des activités lipasiques qui peuvent être très différentes, l'amplitude de variation de ces activités étant voisine de 1 à 10 . La répartition des souches en fonction de leur activité présente les caractères d'une distribution de type bimodal, deux sous-groupes homogènes peuvent être distingués. Entre les activités lipasiques et protéasiques extracellulaires une corrélation positive est mise en évidence.

\section{Introduction}

Penicillium caseicolum Bainier forme à la surface de nombreux fromages à pâte molle le feutrage blanc et il est souvent attribué à cette moisissure un rôle essentiel dans la maturation des pâtes tant en raison de son action désacidifiante que de son aptitude à produire des enzymes susceptibles de dégrader les constituants du caillé, protéines et matière grasse notamment.

L'action lipolytique de $P$. caseicolum a bien été mise en évidence mais elle reste encore assez mal connue. Ainsi, sur les fromages de type Camembert, les acides gras libres pouvant résulter d'une hydro-

(1) Travail réalisé dans le cadre d'un contrat de la Délégation Générale à la Recherche Scientifique et Technique. Contrat n 6701037 sur l'emploi d'enzymes d'origine microbienne dans l'affinage des fromages. 
lyse des glycérides ont fait l'objet de plusieurs travaux (Villette et al., 1959 ; Kuzdzal et Kuzdzal-Savoie, 1966 ; Hote-Baudard, 1967). Des proportions appréciables d'acides gras ont été décelées et l'on peut penser que les lipases de $P$. caseicolum interviennent pour une part importante dans cette libération car la lipolyse est plus prononcée dans la partie externe de la pâte (Kuzdzal-Savoie, 1968).

L'activité lipasique de $P$. caseicolum a cependant été peu étudiée. Proks et Cingrosova (1962) ont comparé les activités de $P$. caseicolum et $P$. camemberti en déterminant l'importance de la lipolyse sur des cultures de 14, 28 et $35 \mathrm{j}$ en milieu de Czapek-Dox additionné de 10 p. 100 de matière grasse de beurre. Dans ces conditions la libération des acides gras est plus importante sur les cultures de $P$. caseicolum que sur celles de $P$. camemberti et, parmi les acides gras libérés, les acides volatils dominent.

L'importance de $P$. caseicolum en technologie, justifie une étude plus large et plus complète de cette activité lipolytique, et il nous a paru intéressant, avant d'aborder l'étude systématique des caractères du système lipasique, de déterminer, sur un grand nombre de souches de diverses origines, l'aptitude de l'espèce à la production de lipase.

\section{Protocole expérimental}

\section{$1^{\circ}$ Matériel D'ÉTUde}

Les souches de Penicillium caseicolum proviennent de la collection constituée au laboratoire et ont diverses origines : fromages de différents types en cours de maturation, murs de caves d'affinage, suspensions commerciales de spores, autres collections (Lenoir et Choisy, 1971) ; sur les 108 souches isolées, 89 ont été conservées pour l'étude de l'aptitude de l'espèce à la production de lipases exocellulaires.

\section{$2^{\circ}$ CONDITIONS DE CULTURE}

Chaque souche pure, entretenue sur milieu gélosé à base de caséine, est ensemencée sur pâte de farine de blé et de seigle. Après $10 \mathrm{j}$ d'incubation, à partir de cette dernière culture, une supension de spores dans du Ringer au 1/4 est préparée et le nombre de spores est déterminé par une mesure d'absorption à $650 \mathrm{~m} \mu$. La suspension de spores, diluée à un taux convenable, est alors ensemencée sur un milieu liquide, dérivé du milieu de Czapek-Dox (Thom et Raper, 1945), dont la composition est la suivante :

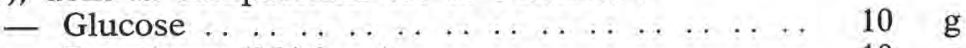

- Trypticase (Mérieux) . . . . . . . . . . . . . . 10 g

- Extrait de levure (Mérieux) .. . . . . . . . . . . 5 g

- Sulfate de magnésium, $7 \mathrm{H}_{2} \mathrm{O} \ldots \ldots \ldots \ldots$. . . . . . $0,5 \mathrm{~g}$

- Chlorure de potassium . . . . . . . . . . . . . $\quad 0,0,5$ g 


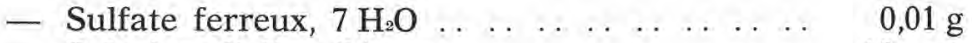

- Solution d'oligo-éléments .

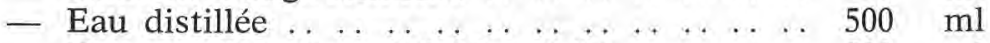

- Tampon phosphate, 0,2 M, pH 7,5 .. . . . . $500 \mathrm{ml}$

La solution aqueuse d'oligo-éléments contient pour $100 \mathrm{ml}$ (Meyers et Knight, 1958) :

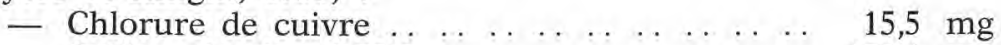

- Sulfate de zinc, $7 \mathrm{H}_{2} \mathrm{O} \ldots \ldots \ldots \ldots$. . . . . . . . . . . 175,6 mg

- Chlorure de manganèse, $4 \mathrm{H}_{2} \mathrm{O} \quad \ldots \quad \ldots \ldots$. . . . $36 \quad 36$ mg

- Chlorure de calcium, $2 \mathrm{H}_{2} \mathrm{O}$. . . . . . . . . . . . 183,4 mg

- Molybdate d'ammonium, $4 \mathrm{H}_{2} \mathrm{O}$. . . . . . . . 10,2 mg

Le milieu de culture est préparé en deux temps ; le milieu sans glucose, réparti en erlenmeyers de $150 \mathrm{ml}$ à raison de $30 \mathrm{ml}$ par fiole, est d'abord stérilisé par autoclavage à $120^{\circ} \mathrm{C}$ pendant $20 \mathrm{mn}$; $10 \mathrm{ml}$ d'une solution aqueuse de glucose à 4 p. 100, stérilisés séparément à $115^{\circ} \mathrm{C}$ pendant $15 \mathrm{mn}$, sont ensuite ajoutés aseptiquement au contenu de chaque erlenmeyer ; le volume final par erlenmeyer est ainsi de $40 \mathrm{ml}$ et le $\mathrm{pH}$ du milieu 7,3 - 7,5.

Chaque souche est ensemencée sur trois fioles à un taux de 10000 spores par $\mathrm{ml}$ de milieu. La culture se développe en étuve à $20^{\circ} \mathrm{C}$ pendant $12 \mathrm{j}$ sans agitation.

L'ensemble de l'étude a comporté six séries d'essais, 15 à 20 souches étant éprouvées simultanément.

\section{3o Détermination DE L'ACTIVITÉ LiPASIQue}

\subsection{Préparation enzymatique}

Le milieu de culture, filtré sur papier filtre de qualité courante, constitue l'extrait enzymatique extracellulaire. Les mesures d'activité sont réalisées dans la journée.

\subsection{Mesures au pH stat}

L'activité lipasique est déterminée selon la méthode de Desnuelle et al. (1955). Les acides gras libérés à partir d'une émulsion de triglycérides sont titrés automatiquement, en continu, le $\mathrm{pH}$ étant maintenu constant. Les conditions opératoires ont été modifiées en fonction de la nature de l'extrait enzymatique et de la qualité du substrat employé, la tributyrine.

\subsubsection{Appareillage}

Combi-titreur 3 D Metrohm ; vase à réaction EA 876-5 thermostaté par circulation d'eau ; électrode EA 121 UX.

\subsubsection{Préparation de l'émulsion}

- Tributyrine (Prolabo) ... . . . . . . . . . . . . . . $10 \mathrm{ml}$

- Solution à 1 p. 100 de Tween $20 \ldots \ldots$. . . . . $1 \mathrm{ml}$

- Eau distillée .................... . .... $100 \mathrm{ml}$ 
Le mélange est agité pendant $1,30 \mathrm{mn}$ avec un appareil UltraTurrax à la vitesse maximale. L'émulsion est ensuite dégazée sous un vide faible. Elle est utilisée dans les $6 \mathrm{~h}$ qui suivent sa préparation.

3.2.3. Mélange de digestion

- Emulsion de tributyrine à 10 p. $100 \ldots \ldots$.. . . 5 ml

- Solution de tampon tris- $\mathrm{HCl} 0,0025 \mathrm{M}, \mathrm{pH} 8,8$

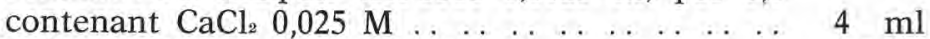

- Solution de phosphate disodique 0,2 M ... . . $0,0,5 \mathrm{ml}$

- Extrait enzymatique . . . . . . . . . . . . . . . . . $\quad 0,5 \mathrm{ml}$

Le mélange de digestion est préparé extemporanément avant chaque mesure dans le vase à réaction.

Avant l'introduction de l'extrait enzymatique, le $\mathrm{pH}$ du mélange est ajusté à une valeur correspondant à $0,1-0,2$ unité au-dessus du $\mathrm{pH}$ de consigne qui est 7,5 ; ce $\mathrm{pH}$ est atteint dès l'addition de l'extrait enzymatique.

\subsubsection{Conditions des mesures}

Le mélange de digestion est maintenu 5 à $10 \mathrm{mn}$ à $30^{\circ} \mathrm{C}$, sous un faible courant d'azote dépourvu de $\mathrm{CO}_{2}$ et la titration de l'acide butyrique libéré est effectuée avec une solution de soude 0,05 $\mathrm{N}$.

Les blancs, réalisés avec des extraits enzymatiques inactivés par chauffage $5 \mathrm{mn}$ à $100^{\circ} \mathrm{C}$ ou avec le milieu de culture stérile, correspondent à des valeurs très faibles qui ne modifient pratiquement pas les résultats.

L'unité lipasique est définie comme la quantité d'enzymes qui libère, dans les conditions de l'essai, un micro-équivalent acide par mn. Les résultats sont exprimés en unité lipase par ml d'extrait enzymatique (U.L./ml).

\subsection{Mesures des variations de $p H$}

Sur une émulsion de tributyrine faiblement tamponnée l'action des lipases se traduit par une variation de $\mathrm{pH}$ et la mesure de la vitesse de cette variation permet d'estimer l'activité enzymatique.

\subsubsection{Appareillage}

- pH-mètre Metrohm E 300 B avec électrode EA 121 UX, temps.

- enregistreur du multidosigraphe E 425 pour la mesure du

\subsubsection{Mélange de digestion}

- Emulsion de tributyrine à 10 p. $100 \ldots \ldots$. . . . $\quad 1,5 \mathrm{ml}$

- Solution de tampon tris- $\mathrm{HCl} 0,05 \mathrm{M}$, pH 8,8,

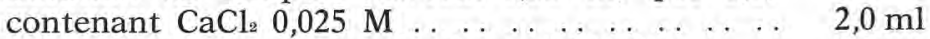

- Solution de phosphate disodique 0,04 M . . . . $1,0 \mathrm{ml}$

- Extrait enzymatique .. . . . . . . . . . . . . . . . $0,5 \mathrm{ml}$

Après addition de l'extrait enzymatique, le $\mathrm{pH}$ du milieu de digestion est voisin de 8,0 . 


\subsubsection{Conditions de la détermination}

La digestion est conduite dans des tubes de polyallomère de $12 \mathrm{ml}$ environ, à la température de $30^{\circ} \mathrm{C}$, pendant un temps variant de 2 à $10 \mathrm{mn}$; la variation de $\mathrm{pH}$ au cours de la digestion ne doit pas dépasser une unité $\mathrm{pH}$.

Dans les conditions expérimentales choisies il y a proportionnalité entre les variations de $\mathrm{pH}$ et la quantité d'extrait ou le temps de digestion.

L'unité d'activité est définie comme la quantité d'enzymes qui provoque une variation de $\mathrm{pH}$ de 0,1 unité en $1 \mathrm{mn}$. Les résultats sont exprimés en unités d'activité par ml d'extrait.

Les essais à blanc, réalisés avec des extraits enzymatiques inactivés par chauffage ou avec le milieu de culture stérile, donnent des valeurs négligeables, inférieures à 0,1 unité d'activité.

$4^{\circ}$ Contrôle de LA CRoissance ET DE L'ACtivité PRotéasique deS CULTURES

Outre l'activité lipasique extracellulaire, sur les cultures obtenues à partir de chaque souche, ont été déterminés le poids de mycélium sec, le $\mathrm{pH}$ du milieu et l'activité protéasique extracellulaire dans les conditions précisées antérieurement (Lenoir et Choisy, 1971).

\section{Résultats}

$1^{\circ}$ MISE AU POINT DES CONDITIONS OPÉRATOIRES

\subsection{Conditions de détermination de l'activité lipasique}

La mise au point de la méthode de détermination de l'activité fondée sur les mesures des variations de $\mathrm{pH}$ a été réalisée en utilisant des préparations enzymatiques provenant de diverses souches.

\subsubsection{Influence du $\mathrm{pH}$ du mélange de digestion}

Le $\mathrm{pH}$ optimal d'action de l'extrait enzymatique, déterminé au $\mathrm{pH}$-stat, se situe vers 8,5 ; aux $\mathrm{pH} 8$ et 7 , les activités sont respectivement proches de 96 et 83 p. 100 de l'activité optimale.

Dans l'intervalle de $\mathrm{pH}$ 8-7 les variations d'activité de l'extrait enzymatique sont donc faibles et les proportions d'acide butyrique titrables sont proches de 100 p. 100 ; aussi observe-t-on, dans cet intervalle, avec la composition du mélange choisie, que la variation de $\mathrm{pH}$ est proportionnelle au temps de digestion, dans les limites de $0-15 \mathrm{mn}$ (fig. 1) ; la courbe peut alors être assimilée à une droite et la pente de celle-ci traduit l'activité lipasique. 


\subsubsection{Influence de la quantité d'enzymes}

Des préparations enzymatiques ont été diluées à différents taux, soit avec le milieu de culture stérile, soit avec un tampon phosphate $0,1 \mathrm{M}$ à $\mathrm{pH} 8$. Les courbes de la figure 2 montrent que la vitesse de variation $\mathrm{du} \mathrm{pH}$ est proportionnelle à la quantité d'extrait enzymatique pour des quantités d'enzymes inférieures à 12 unités.

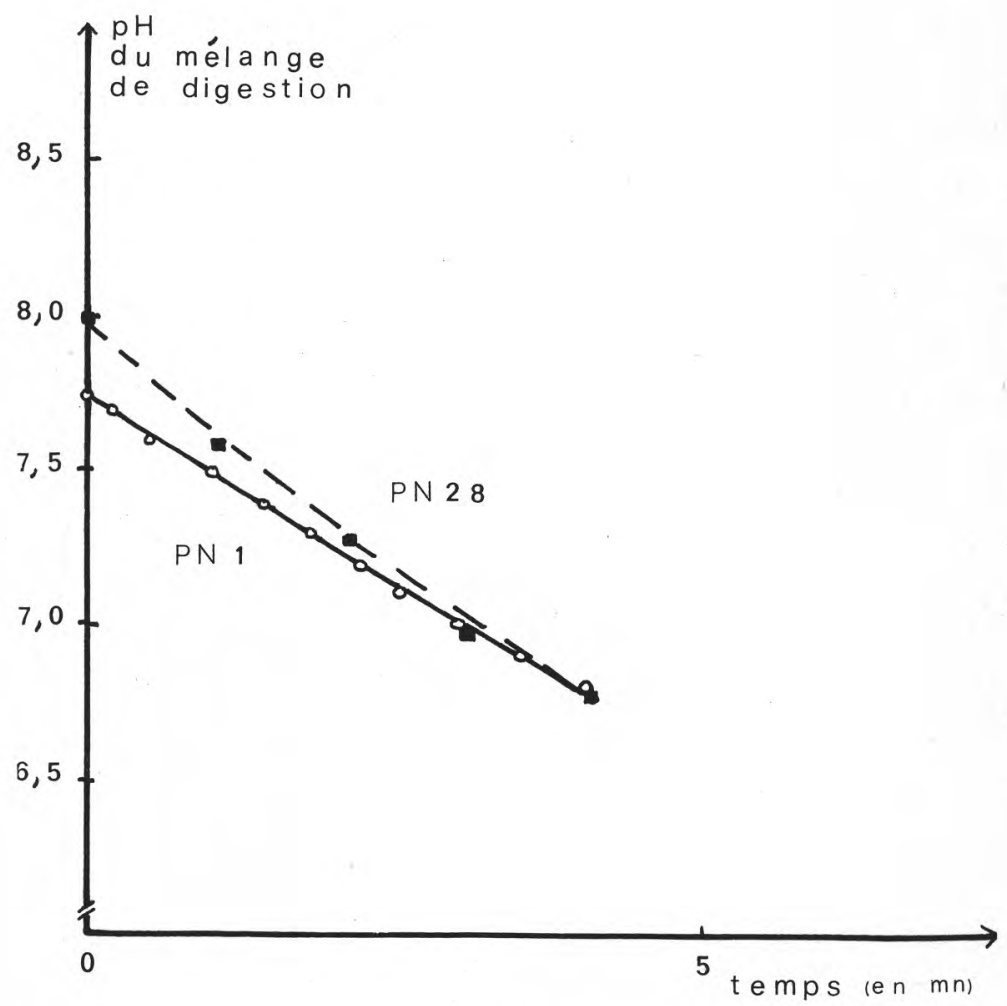

fig. 1

Evolution du $\mathrm{pH}$ du mélange de digestion pour 2 filtrats de culture de souches différentes.

- en abscisses : temps en mn,

- en ordonnées : $\mathrm{pH}$ du mélange de digestion.

Conditions des essais : Conditions des déterminations d'activité par mesure des variations de $\mathrm{pH}$. 


\subsubsection{Influence de la température de digestion}

Avec des temps de digestion de 5 à $10 \mathrm{mn}$, la température optimale d'action des préparations enzymatiques est de $30^{\circ} \mathrm{C}$; à $20-35$ et $40^{\circ} \mathrm{C}$, les activités sont respectivement $91-94$ et 71 p. 100 de l'activité optimale.

\subsubsection{Comparaison des résultats obtenus par les deux méthodes}

Sur un certain nombre de préparations enzymatiques, provenant de cultures de 7 souches différentes, les mesures d'activité ont été réalisées selon les deux méthodes, $\mathrm{pH}$-stat et variation de $\mathrm{pH}$.

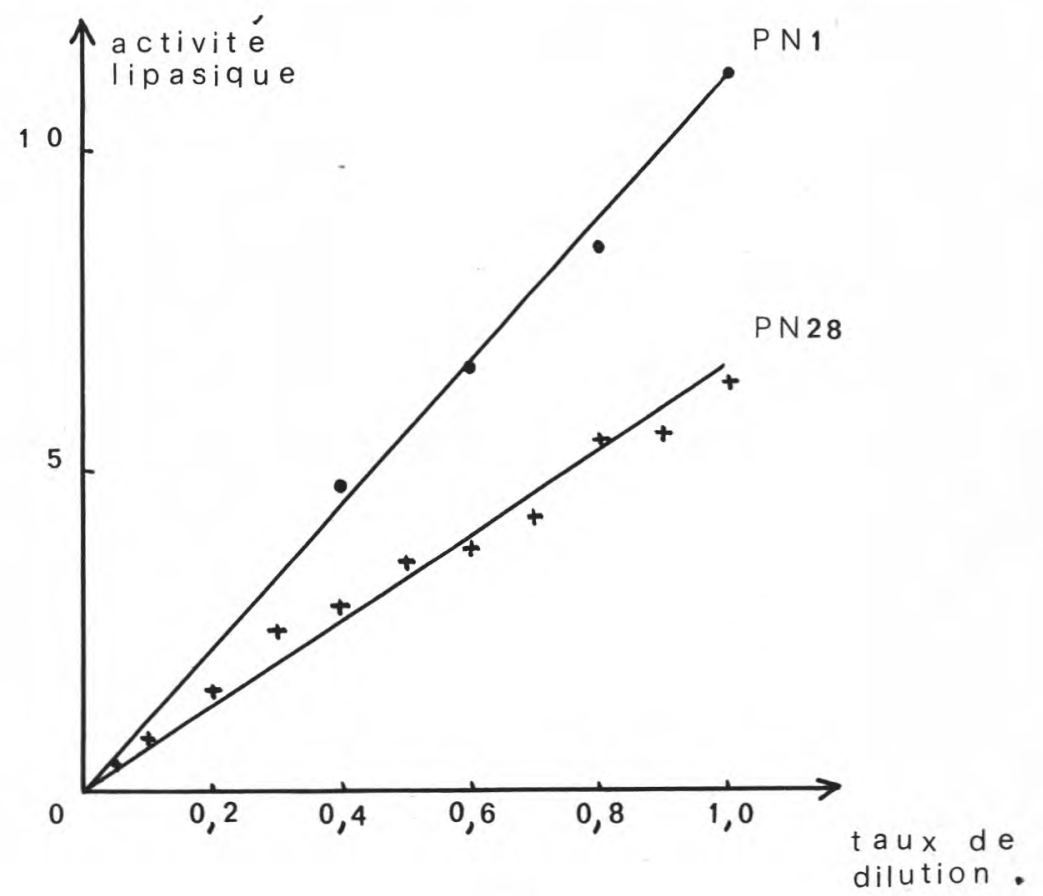

fig. 2

Influence de la quantité d'enzymes sur le degré d'hydrolyse de la tributyrine.

- en abscisses : taux de dilution des extraits enzymatiques (dilution en tampon phosphate $0,1 \mathrm{M}$ ),

- en ordonnées : activité lipasique, en $1 / 10^{\mathrm{e}}$ d'unité $\mathrm{pH} / \mathrm{mn}$ pour $1 \mathrm{ml}$ de préparation enzymatique.

Conditions des essais :

- culture : milieu Czapek-Trypticase + extrait de levure, $\mathrm{pH}$ 7,5, incubation $12 \mathrm{j}$ à $20^{\circ} \mathrm{C}$ sans agitation,

- détermination des activités par mesure des variations de $\mathrm{pH}$. 
Les résultats sont représentés sur la figure 3. Les points figuratifs se répartissent le long d'une droite. Le calcul donne un coefficient de corrélation positif de 0,99 et l'équation de la droite de régression est : $\mathrm{Y}=0,5+0,104 \mathrm{X}$.

Ces données montrent que les résultats des mesures des variations de $\mathrm{pH}$ concordent avec les valeurs obtenues avec la méthode au pH-stat. Il est ainsi possible d'estimer l'activité lipasique des

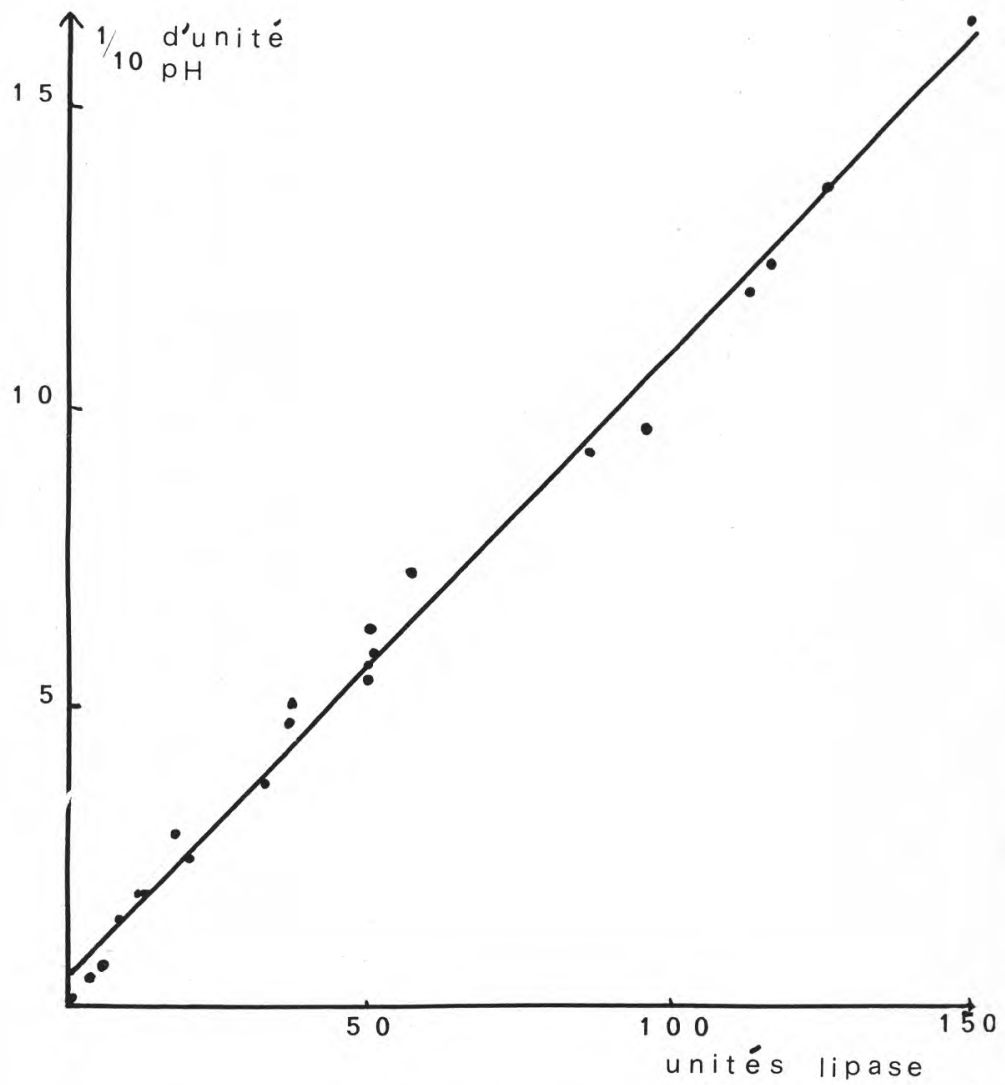

fig. 3

Relation entre les résultats obtenus par les deux méthodes de mesure d'activité lipasique.

- en abscisses : activités mesurées à $\mathrm{pH}$ constant exprimées en micro-équivalents acide libéré par $\mathrm{mn}$ et par ml d'extrait,

- en ordonnées : activités mesurées par la méthode de variation de $\mathrm{pH}$, exprimées en $1 / 10^{\mathrm{e}}$ d'unité $\mathrm{pH}$ par $\mathrm{mn}$ et par ml d'extrait. 
cultures plus rapidement que par mesures à $\mathrm{pH}$ constant et avec une méthode se prêtant mieux aux déterminations en série.

L'équation de la droite de régression permet d'établir une correspondance entre les unités définies dans l'une et l'autre méthodes; une unité de la méthode "variation de $\mathrm{pH}$ ", c'est-à-dire une variation de 0,1 unité $\mathrm{pH}$ par $\mathrm{mn}$ et par $\mathrm{ml}$ de préparation enzymatique, correspond à environ 9 unités lipase par $\mathrm{ml}$.

\subsection{Conditions de cultures}

Les conditions de culture favorables à la production de lipases ont été recherchées avec deux souches.

Divers auteurs, dont Thibodeau et Macy (1942) et Imamura et Kataoka (1963) pour Penicillium roqueforti, Nelson (1953) et Alford et Smith (1965) pour Geotrichum candidum ont trouvé de plus fortes productions de lipases sur des milieux contenant une source d'azote organique. Aussi avons-nous pris, comme milieu de base, le milieu Czapek-trypticase dérivé du milieu de Czapek-Dox par apport d'une source d'azote peptidique au lieu du nitrate de sodium (Lenoir et Choisy, 1971).

La recherche des conditions favorables à la production d'enzymes a comporté une étude sommaire de l'influence de la composition du milieu et de certains facteurs physiques et physico-chimiques. L'intérêt d'une supplémentation du milieu Czapek-trypticase par addition d'extrait de levure et d'un ajustement du $\mathrm{pH}$ initial du milieu à une valeur proche de 7,5 a notamment été mis en évidence. Parallèlement il a été constaté qu'un taux d'ensemencement de 10000 spores par $\mathrm{ml}$, une température d'incubation de $20^{\circ} \mathrm{C}$ et un temps de culture de $12 \mathrm{j}$ en milieu non agité, mais avec une répartition assurant un large contact avec l'air, permettaient d'assurer une production de lipases satisfaisante.

1.2.1. Influence de la teneur en glucose et de la présence d'extrait de levure

Des concentrations de $5-10-20$ et $50 \mathrm{~g} / 1$ de glucose ont été essayées, en présence ou non d'extrait de levure ( $5 \mathrm{~g}$ par 1) pour les concentrations 10 et $20 \mathrm{~g} / \mathrm{l}$. Les différences dans les niveaux de production d'enzymes sont faibles; toutefois, la concentration en glucose de $10 \mathrm{~g} / 1$, en présence de $5 \mathrm{~g} / 1$ d'extrait de levure, est la plus favorable avec les deux souches. Aux fortes concentrations en glucose, l'acidification du milieu est probablement à l'origine de la moindre production d'enzymes.

\subsubsection{Influence du $\mathrm{pH}$ initial du milieu.}

Cet essai a été réalisé avec le milieu Czapek-trypticase non modifié dans sa composition mais, afin de limiter les variations de $\mathrm{pH}$ au cours de la stérilisation, le glucose a été stérilisé séparément, en solution aqueuse, et ajouté ensuite aseptiquement. 
Pour un $\mathrm{pH}$ initial variant de 5,5 à 8,0 l'on note qu'avec les deux souches, les $\mathrm{pH}$ de fin de culture tendent vers $7,2-7,4$; les poids de mycélium diminuent légèrement lorsque le $\mathrm{pH}$ initial de la culture augmente ; en revanche, la production maximale de lipases est obtenue pour un $\mathrm{pH}$ initial proche de 7,5. L'influence du $\mathrm{pH}$ sur cette production est particulièrement nette et il est probable que le manque de stabilité de l'enzyme en milieu acide explique, au moins en partie, le faible niveau de production pour des $\mathrm{pH}$ initiaux voisins de 5,5 - 6 bien que les $\mathrm{pH}$ de fin de culture se situent toujours audessus de 6,5 .

\subsubsection{Influence du temps de culture}

Avec le milieu Czapek-trypticase additionné d'extrait de levure et ajusté à $\mathrm{pH} 7,5$ le poids de mycélium est maximal au $10^{\text {me }} \mathrm{j}$; le $\mathrm{pH}$ de fin de culture évolue peu entre le $10^{\text {me }}$ et le $12^{\text {me }} \mathrm{j}$; la production de lipases est maximale le $12^{\text {me }} \mathrm{j}$ pour une souche, elle s'accroît jusqu'au $14^{\text {me }} \mathrm{j}$ pour l'autre (tab. 1).

\subsubsection{Les autres conditions de culture adoptées}

Température, taux d'ensemencement, non agitation et mode de répartition du milieu sont celles qui ont été retenues pour l'étude de l'aptitude de $P$. caseicolum à la production d'enzymes protéolytiques (Lenoir et Choisy, 1971). Il a été simplement vérifié qu'elles étaient également favorables à la production de lipases.

\section{TABLEAU 1}

Influence du temps d'incubation sur la production de lipase par Penicillium caseicolum

\begin{tabular}{c|c|c}
\hline \multirow{2}{*}{ Souches } & $\begin{array}{c}\text { Temps d'incubation } \\
\text { (en jours) }\end{array}$ & Activités lipasiques* \\
\hline $\mathrm{P}_{1}$ & 10 & 4,7 \\
& 12 & 5,9 \\
14 & 7,4 \\
$\mathrm{PN}_{1}$ & 10 & 10,1 \\
& 12 & 14,0 \\
& 14 & 11,6 \\
\hline
\end{tabular}

* en $1 / 10^{\text {e d} u n i t e ́ ~} \mathrm{pH}$ par $\mathrm{mn}$ et par $\mathrm{ml}$ de préparation.

Conditions des essais :

Culture sur milieu Czapek-trypticase additionné d'extrait de levure, $\mathrm{pH}$ 7,5, température $20^{\circ} \mathrm{C}$, ensemencement sur 3 erlenmeyers. 


\section{2。 CROISSANCE ET ACTIVITÉ LIPASIQUE DES SOUCHES}

Sur les cultures obtenues, soit pour chaque souche trois erlenmeyers, sont déterminés, après les $12 \mathrm{j}$ d'incubation, le $\mathrm{pH}$ final du milieu, le poids de mycélium sec et les activités protéasique et lipasique extracellulaires.

Dans les conditions de culture mises en œuvre la croissance du mycélium et l'évolution du $\mathrm{pH}$ du milieu sont reproductibles dans

\section{TABLEAU 2}

Reproductibilité des résultats de la détermination des activités lipasiques

a) Reproductibilité dans une même série d'essais (résultats des 3 essais obtenus avec les 10 premières souches de la série 1).

\begin{tabular}{l|c}
\hline \multirow{2}{*}{ Numéro des souches } & Activités lipasiques \\
$\mathrm{P}_{1}$ & $5,5-6,1-5,05$ \\
$\mathrm{P}_{2}$ & $3,35-4,1-3,55$ \\
$\mathrm{P}_{5}$ & $3,85-3,6-4,0$ \\
$\mathrm{P}_{8}$ & $3,5-3,9-3,75$ \\
$\mathrm{P}_{11}$ & $3,75-5,1-4,6$ \\
$\mathrm{P}_{12}$ & $3,25-3,45-3,45$ \\
$\mathrm{P}_{13}$ & $2,80-4,1-2,95$ \\
$\mathrm{P}_{20}$ & $2,8-2,55-2,6$ \\
$\mathrm{P}_{23}$ & $6,1-5,1-6,3$ \\
$\mathrm{PL}_{1}$ & $5,0-5,95-6,1$ \\
\hline
\end{tabular}

b) Reproductibilité dans les séries d'essais différentes.

\begin{tabular}{c|c|c|c|c|c|c}
\hline & \multicolumn{6}{c}{ Activités moyennes dans les séries $\mathrm{n}^{\circ}$} \\
\cline { 2 - 6 } $\begin{array}{c}\text { Numéros } \\
\text { des souches }\end{array}$ & 1 & 2 & 3 & 4 & 5 & 6 \\
& & & & & & \\
\hline & 5,55 & 5,7 & & 4,5 & 5,9 & 5,05 \\
$\mathbf{P}_{1}$ & 3,50 & 4,5 & & 4,5 & 5,4 & \\
$\mathbf{P}_{12}$ & 5,4 & 5,35 & & 5,3 & 6,0 & 4,44 \\
$\mathbf{P L}_{3}$ & 5,5 & 5,5 & 1,15 & 5,1 & & \\
$\mathbf{P L}_{7}$ & 2,65 & 1,65 & 1,9 & & & \\
$\mathbf{P}_{13}$ & & & & & & \\
$\mathbf{P}_{20}$ & & &
\end{tabular}

Conditions des essais :

Culture sur milieu Czapek-trypticase additionné d'extrait de levure, pH 7,5. Incubation $12 \mathrm{j}$ à $20^{\circ} \mathrm{C}$ sans agitation, ensemencement de 3 erlenmeyers par souche.

Activité lipasique mesurée par la méthode de "variation de $\mathrm{pH}$ "; résultats exprimés en $1 / 10^{\circ}$ d'unité $\mathrm{pH}$ par $\mathrm{mn}$ et par $\mathrm{ml}$ de préparation enzymatique. 
une même série d'essais ainsi que d'une série d'essais à l'autre. En revanche, en ce qui concerne les activités lipasiques les différences de résultats dans une même série d'essais ne sont pas négligeables (tab. 2). Ces différences imposent de réaliser les essais au moins en triple exemplaire et seuls des écarts notables dans l'activité des souches pourront être considérés comme réellement significatifs.

D'une série d'essais à l'autre on trouve entre les activités linasiques moyennes des différences qui peuvent être encore plus élevées, notamment avec les souches P12 et PL 3, et l'on observe que les valeurs maximales correspondent à la série 5 , les valeurs minimales à la série 6 (sauf pour la souche $\mathrm{P} 1$ ). Afin de limiter l'influence de ces variations, une correction a été apportée aux résultats des séries $2,3,4,5$ et 6 , la série 1 ayant été prise comme référence. Exception faite pour la souche $\mathrm{P} 12$, les coefficients de correction déterminés à partir des différentes souches témoin ont des valeurs comparables et un coefficient de correction moyen a pu être appliqué.

Les répartitions des souches en fonction du poids de mycélium et de la production de lipase sont représentées sur les histogrammes des figures 4 et 5 .

Le $\mathrm{pH}$ de fin de culture varie de 7,65 à 8,55 , le poids de mycélium sec oscille entre 0,50 et $0,80 \mathrm{~g}$ pour $100 \mathrm{ml}$ de milieu, l'activité lipasique extracellulaire est comprise entre 0,9 et 11 unités de la méthode proposée.

\section{Discussion}

L'étude des facteurs de production est certes trop sommaire pour que des conclusions rigoureuses puissent être tirées. Il apparaît cependant que le $\mathrm{pH}$ initial du milieu de culture a une très grande influence sur le niveau de production d'enzymes et l'on observe qu'une différence de 0,5 unité de part et d'autre du $\mathrm{pH}$ optimal 7,5 peut se traduire par une diminution très sensible de l'activité lipasique extracellulaire. Une forte proportion de glucose n'est pas favorable à la production d'enzymes bien qu'elle soit à l'origine d'un accroissement de poids de mycélium. Sans doute faut-il voir là une conséquence de l'acidification du milieu provoquée par les teneurs en glucose élevées.

On constate ainsi chez Penicillium caseicolum une différence très nette entre le $\mathrm{pH}$ optimal de production du système protéolytique et celui du système lipasique, le premier se situant en zone acide dans l'intervalle 5,5-6,5 (Lenoir et Choisy, 1971).

Des observations analogues ont été faites avec Penicillium roqueforti. Niki et al. (1966) notent, chez cette moisissure cultivée sur lactosérum, une plus forte production de lipase à $\mathrm{pH}$ neutre ou alcalin, alors que la production de protéase est optimale en milieu acide. D'autres auteurs (Thibodeau et Macy, 1942 ; Imamura et Kataoka, 
1963) relèvent que la présence de glucose en forte concentration tend à retarder ou diminuer la production de lipase. L'on notera cependant que sur une souche de $P$. roqueforti, Eitenmiller (1968) obtient un maximum de production de lipase exocellulaire à $\mathrm{pH} 5,5, \mathrm{pH}$ qui correspond également à la croissance maximale.

Dans les conditions de développement mises en œuvre les souches de $P$. caseicolum révèlent des activités lipasiques très différentes. L'amplitude de variation de ces activités couvre en effet un

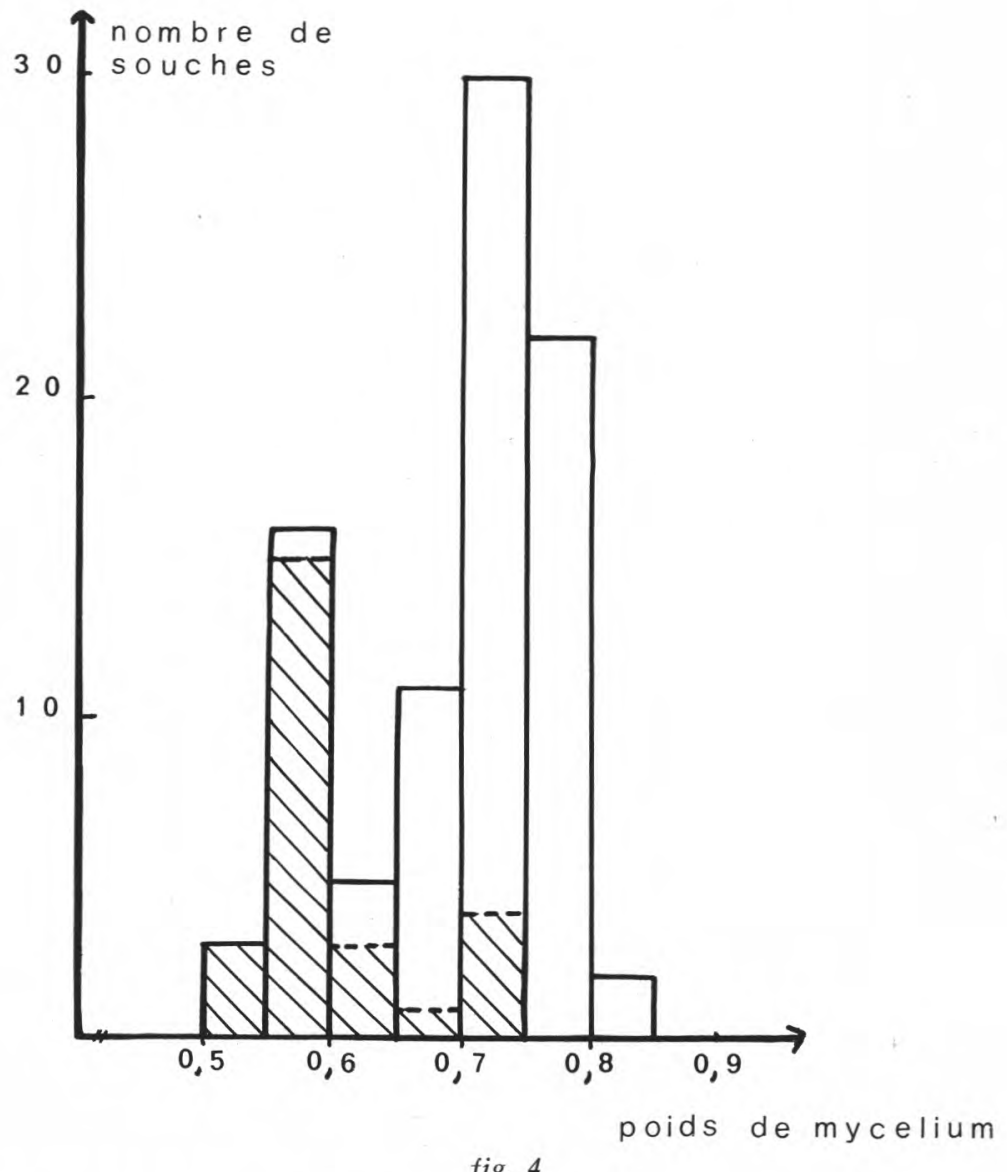

fig. 4

Distribution des souches de $P$. caseicolum en fonction du poids de mycélium.

- en abscisses : les classes de poids, les poids étant exprimés en g de mycélium sec pour $100 \mathrm{ml}$ de milieu,

- en ordonnées : le nombre de souches appartenant aux différentes classes.

La partie hachurée correspond aux souches d'origine Neufchâtel. 
intervalle proche de 1 à 10 . Toutefois, 45 souches, soit la moitié de la population étudiée, ont une activité comprise entre 3,2 et 5,6 unités et la moyenne générale des activités est proche de 5,1.

L'allure assymétrique de l'histogramme illustrant la répartition des souches en fonction de leur activité lipasique (fig. 5) tend à indiquer qu'il ne s'agit pas d'une distribution de type unimodal. La

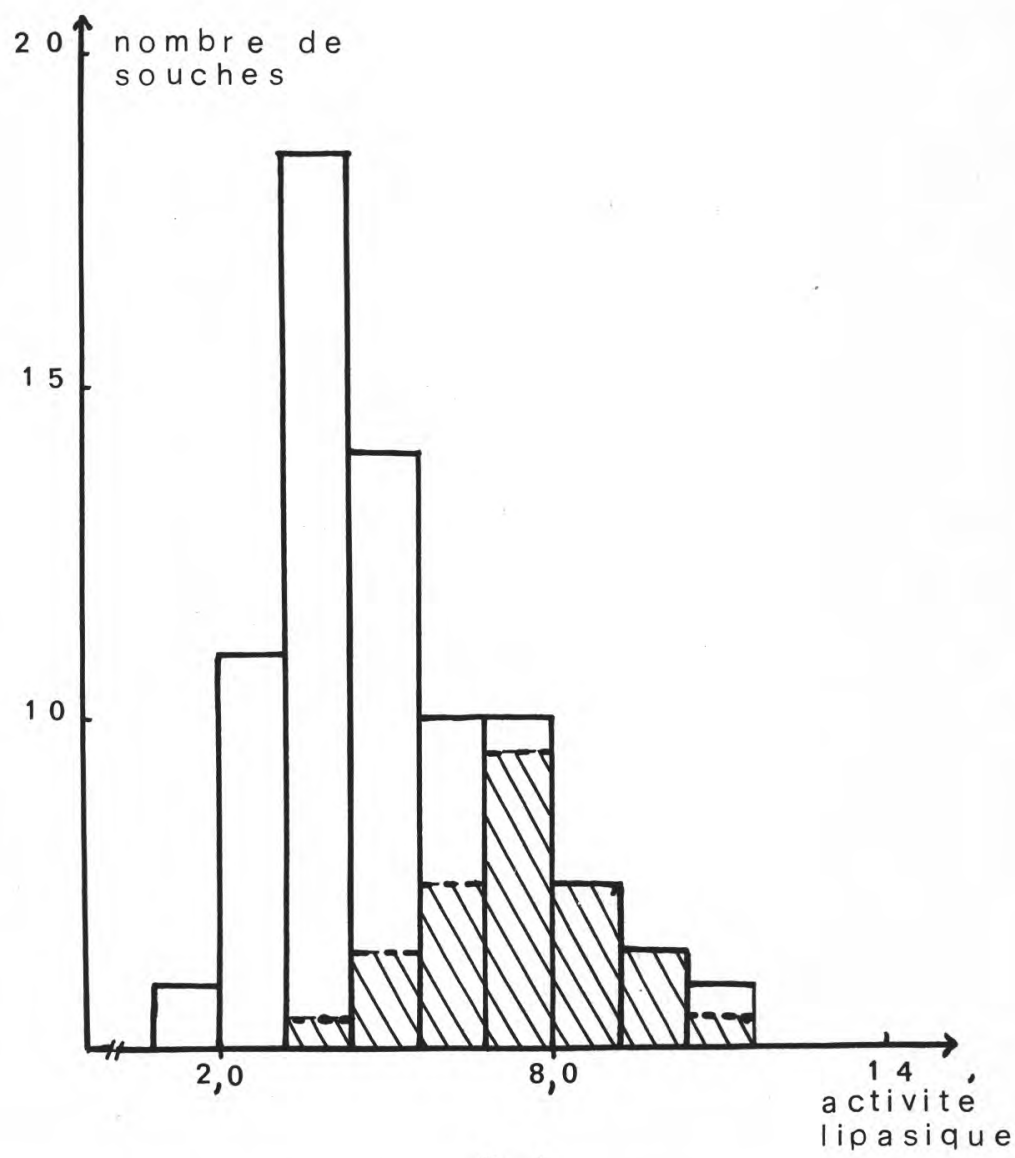

fig. 5

Distribution des souches de $P$. caseicolum en fonction de leur production de lipase extracellulaire.

- en abscisses : les classes d'activité lipasique mesurée par la méthode de variation de $\mathrm{pH}$, résultats exprimés en $1 / 10^{\mathrm{e}}$ d'unité $\mathrm{pH}$ par $\mathrm{mn}$ et par $\mathrm{ml}$ d'extrait,

- en ordonnées : le nombre de souches appartenant aux différentes classes.

La partie hachurée correspond à la distribution des souches d'origine Neufchâtel. 
répartition des 26 souches d'origine Neufchâtel dans l'ensemble de la population confirme une telle hypothèse car toutes ces souches forment un sous-groupe homogène dont la courbe de répartition a les caractères d'une distribution unimodale. Le reste de la population paraît également constituer un sous-groupe homogène et les moyen-

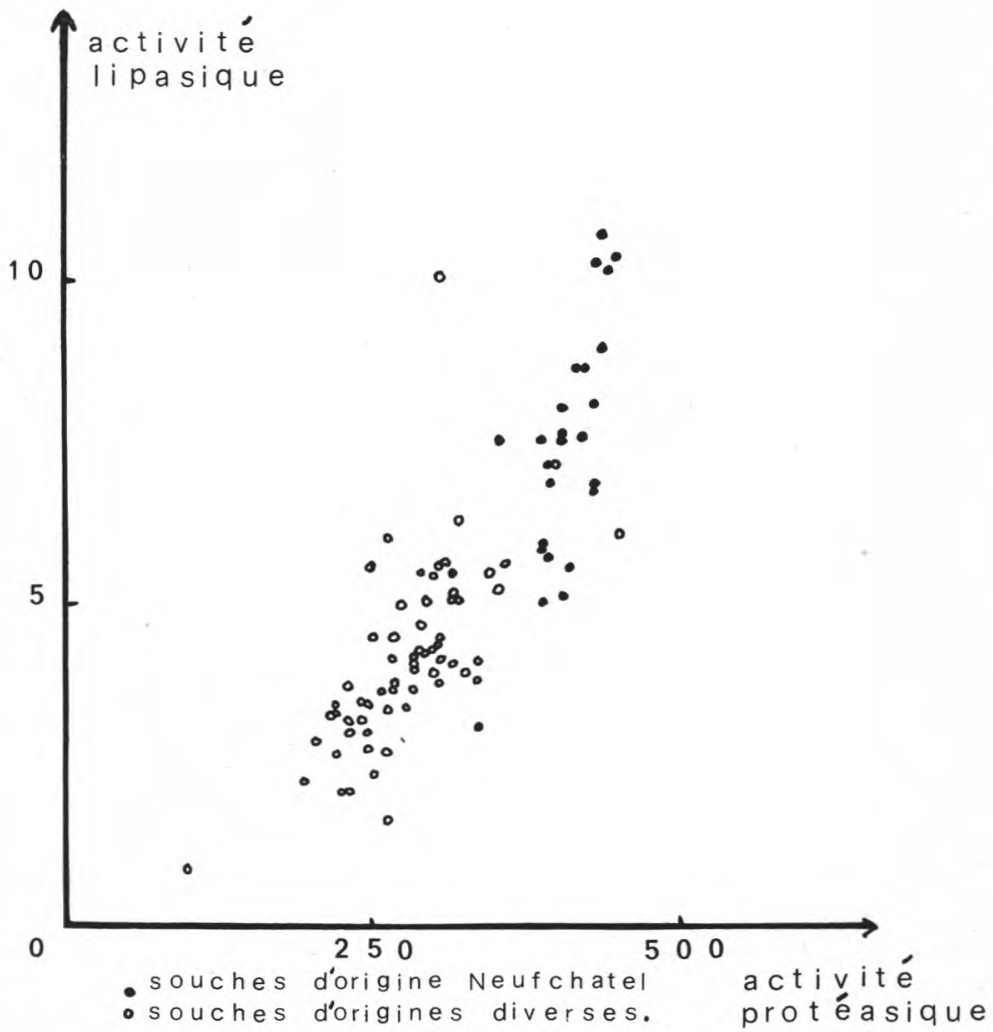

fig. 6

Relation entre les activités lipasiques et protéasiques extracellulaires de P. caseicolum.

- en abscisses : activités protéasiques en $\mu \mathrm{g}$ de tyrosine par $\mathrm{ml}$ de préparation et par heure de digestion,

- en ordonnées : activités lipasiques mesurées par la méthode de variation de $\mathrm{pH}$, résultats exprimés en $1 / 10^{\circ}$ d'unité $\mathrm{pH}$ par mn et par ml d'extrait enzymatique.

Conditions de culture :

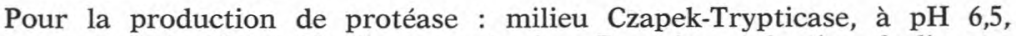
incubation de $12 \mathrm{j}$ à $20^{\circ} \mathrm{C}$, sans agitation. Pour la production de lipase : milieu Czapek-Trypticase + extrait de levure, $\mathrm{pH} 7,5$, incubation de $12 \mathrm{j}$ à $20^{\circ} \mathrm{C}$ sans agitation. 
nes des activités des souches de ces deux sous-groupes sont significativement différentes : 7,4 pour le sous-groupe Neufchâtel, 4,1 pour le reste de la population.

Ces résultats s'accordent avec ceux relatifs à l'aptitude de $P$. caseicolum à la production d'enzymes protéolytiques qui avaient également permis de mettre en évidence l'existence de deux sousgroupes au sein de la population étudiée (Lenoir et Choisy, 1971). Les différences d'activité protéasique entre les souches étaient cependant beaucoup plus faibles, l'amplitude de variation étant voisine de 1 à 2 .

Les résultats concernant la production de mycélium, groupés de 0,5 à 0,8 g p. $100 \mathrm{ml}$, sont relativement homogènes, et l'on n'observe aucune corrélation entre la croissance et la production d'enzymes lipolytiques. En ce qui concerne les valeurs des $\mathrm{pH}$ de fin de culture une variation relativement importante est constatée puisqu'elle atteint près de 1 unité $\mathrm{pH}$, malgré la présence de phosphates à la concentration $0,1 \mathrm{M}$, ceux-ci ne manifestant qu'un effet tampon très limité aux environs de $\mathrm{pH}$ 8. Cette variation ne doit pas avoir d'incidence sur la stabilité des lipases car celle-ci est maximale dans l'intervalle de $\mathrm{pH} 7,5-8,5$. En a-t-elle une sur la production d'enzymes ? La réponse est moins évidente. On ne peut que relever une certaine relation entre l'augmentation du $\mathrm{pH}$ des cultures et le niveau de production de lipases, les souches les plus activement lipolytiques tendent en effet à alcaliniser le milieu davantage que les autres.

Sur le mileu Czapek-trypticase supplémenté en extrait de levure et ajusté à $\mathrm{pH} 7,5$, les activités protéasiques exocellulaires de l'ensemble des souches varient dans des limites relatives étroites, 1 à 2,5 , soit une amplitude de variation proche de celle observée sur le milieu Czapek-trypticase à pH 6,5 (Lenoir et Choisy, 1971). Entre les activités lipasiques et les activités protéasiques déterminées l'une et l'autre sur le milieu à $\mathrm{pH} 7,5$ aucune corrélation n'a pu être mise en évidence ; en revanche en se référant, pour la production des protéases exocellulaires, aux résultats obtenus sur le milieu Czapektrypticase à pH 6,5 (Lenoir et Choisy, 1971), c'est-à-dire dans des conditions favorables à la synthèse des enzymes protéolytiques, une corrélation positive $(r=0,86)$ peut être notée pour l'ensemble des souches (fig. 6).

Une telle corrélation entre les aptitudes à la production d'enzymes protéolytiques et lipolytiques au sein de l'espèce Penicillium caseicolum n'est guère en accord avec les observations faites jusqu'ici par d'autres auteurs. Ainsi Niki et al. (1966) ont relevé une relation inverse entre les activités protéolytiques et lipolytiques sur différentes souches de Penicillium roqueforti isolées de fromages bleus de plusieurs types. De même, Proks et Cingrosova (1962), comparant les activités de $P$. caseicolum et $P$. camemberti, notent que la première espèce présente une activité lipolytique plus forte alors que son activité protéolytique est plus faible. 


\section{Conclusion}

Les différences observées dans l'aptitude des souches de Penicillium caseicolum à la production de lipases extracellulaires sont d'une amplitude telle qu'elles montrent clairement l'intérêt en technologie fromagère, pour une maîtrise de l'évolution des pâtes au cours de la maturation, d'une sélection des souches fondée sur un contrôle rigoureux de ce caractère et non sur les seuls critères d'aspect, de couleur ou d'aptitude à la sporulation.

\section{Remerciements}

Nous remercions vivement $M$. Le Professeur Jacquet et MM. Desfleurs et Emery qui ont bien voulu mettre à notre disposition un certain nombre de souches de leurs collections.

Nos remerciements vont également à $M$. Huet, Assistant à la Chaire d'Agriculture, pour l'aide précieuse qu'il nous a apportée dans l'élaboration des données statistiques.

\section{Summary \\ Aptitude of Penicillium caseicolum in production of lipolytic enzymes}

The aptitude of Penicillium caseicolum lipases has been searched for in a collection of about 100 strains of various origins by cultivation in liquid medium. The lipasic activity has been tested on culture filtrates by measuring the $\mathrm{pH}$ variations in a slightly buffered emulsion of tributyrin. The strains of $P$. caseicolum show lipasic activities that may be quite different, the variations of these activities being possible between 1 and 10 . The repartition of the strains, according to their activity, show the caracteristics of a bimodal type distribution, and two homogeneous under-groups can be distinguished. A positive correlation is shown between the extracellular lipasic and proteolytic activities.

Reçu pour publication le 26 octobre 1971.

\section{Références bibliographiques}

AlfoRd (J. A.) and SMith (J. L.) (1965). - Production of microbial lipases for the study of triglycérides structure. J. Am. Oil. Chem Soc., 42, 1038.

Desnuelle (P.), Constantin (M. J.) et Baldy (J.) (1955). - Technique potentiométrique pour la mesure de l'activité de la lipase pancréatique. Bull. Soc. Chim. Biol., 37 (2-3), 285-290. 
EITENMiller (R. R.) (1968). - Production and properties of a Penicillium roqueforti lipase. Thèse pour le "Degree of Master of Science ", Department of Food Science and Technology, University of Nebraska, Lincoln.

Hote-BaudaRd (F.) (1967). - Contribution à l'étude des acides gras dans les fromages du type Camembert. Bull. Rech. Agr. Gembloux, 2 (4), 667-683.

ImamuRA (T.) and KataOKA (K.) (1963). - Biochemical studies on the manufacturing of Roquefort type cheese. I. Lipase producing ability of Penicillium roqueforti. Jap. J. Zootech. Sci., 34 (5), 344-348.

Kuzdzal (W.) et Kuzdzal-SavoIe (S.) (1966). - Etude comparée des acides gras non volatils libres et estérifiés dans les fromages. C.R. XVII ${ }^{\mathrm{e}}$ Cong. Int. Lait., Vol. D, 335-342.

KuzDzAL-SAvoie (S.) (1968). - Application de la chromatographie sur couche mince à l'étude de la lipolyse dans les fromages. Qualitas Plantarum et Mat. végét., 16 (1-4), 312-319.

Lenoir (J.) et Choisy (C.) (1971). - Aptitude de l'espèce Penicillium caseicolum à la production d'enzymes protéolytiques. Le Lait, 51 (503-504), 138-157.

MEYERS and KNIGHT (1958). - Studies on the nutrition of Penicillium roqueforti. Appl. Microbiol., 6 (3), 174-178.

Nelson (W. O.) (1953). - Nutritional factors affecting growth and production of lipase by Geotrichum candidum. J. Dairy Sci., 36, 143-151.

Niki (T.) Yoshioka (Y.) and Aнiкo (K.) (1966). - Proteolytic and lipolytic activities of Penicillium roqueforti isolated from blue cheese. C.R. XVII ${ }^{\mathrm{e}}$ Cong. Int. Lait., Vol. D, 531-537.

Proks (J.) et Cingrosova (K.) (1962). - The influence of Penicillium camemberti and Penicillium caseicolum on proteolytic and lipolytic changes in the ripening of Camembert cheese type. C.R. XVI ${ }^{e}$ Cong. Int. Lait., Vol. B, 442-448.

Thibodeau (R.) and Macy (H.) (1942). - Growth and enzyme activity of Penicillium roqueforti. Minnesota Agr. Expt. Sta. Tech. Bull., 152.

THOM (C.) and RAPER (K.) (1945). - A manual of the Aspergilli, Williams and Wilkins Co, Baltimore.

Villette (O.), Jacouet (J.) et Letourneur (G.) (1959). - Contribution à l'étude de la maturation des fromages normands à pâtes molles. II. Acides organiques. C.R. Acad. Agric., 45, 849-854. 